\title{
Effect of maternal growth monitoring knowledge on stunting, wasting and underweight among children 0-18 months in Tamale metropolis of Ghana
}

\author{
Mohammed Bukari*i], Muzamil Mohammed Abubakari, Mohammed Majeed, Abdul-Razak Abizari,
} Anthony Wemakor and Ambrose Atosona

\begin{abstract}
Objective: This study sought to assess maternal growth monitoring knowledge and its effect on stunting, wasting and underweight among children 0-18 months in the Tamale Metropolis. An analytical cross-sectional study design, involving 340 mother-child pairs randomly selected from 4 health facilities in the Tamale Metropolis was used. A structured questionnaire was used to collect information on socio-demographic characteristics and maternal growth monitoring knowledge. Weight and length of children were taken to assess nutritional status (stunting, underweight and wasting). Chi square/Fisher's exact test was used to determine the association between maternal growth monitoring knowledge level and child nutritional status.

Results: The study revealed that $87.6 \%$ of mothers had good knowledge on growth monitoring. The prevalence of stunting, underweight and wasting were $9.4 \%, 25.9 \%$ and $17.9 \%$ respectively. Bivariate analysis revealed that there is no association between maternal growth monitoring knowledge and stunting $(p=0.781)$, wasting $(p=0.743)$ and underweight $(p=0.529)$ among children $0-18$ months in the Tamale Metropolis.
\end{abstract}

Keywords: Growth monitoring, Knowledge, Wasting, Stunting, Underweight, Tamale

\section{Introduction}

Child growth monitoring is aimed at improving and maintaining child health and nutrition [1]. It is so far the best strategy carried out worldwide to tackle malnutrition [2]. It involves regular measurement and plotting of a child's weight on a growth chart $[3,4]$. Growth monitoring is a process of regularly following the growth rate of a child in comparison to standard anthropometric measurements [2]. It is usually coupled with promotional activities such as counselling and actions to improve growth, as weighing and charting alone cannot

*Correspondence: mohammed.bukari@yahoo.com

Department of Nutritional Sciences, School of Allied Health Sciences,

University for Development Studies, P. O. Box TL 1883, Tamale, Ghana improve growth $[3,4]$. Assessing growth allows capturing growth faltering before the child reaches the status of under-nutrition thereby reducing the risk of death [5]. According to Schwinger et al. [6], assessing a child's growth trajectory provides a more accurate prognosis of likely death than the use of static measures of nutritional status. Sinaga et al. [7] also revealed that growth monitoring has a positive impact on infant feeding practices and calorie intake.

Growth monitoring is practiced worldwide [8] and its coverage in Ghana is $95.3 \%$ [9]. A79\% coverage has also been reported in the Tamale Metropolis [10]. Despite its wide coverage, the prevalence of malnutrition is still high, indicating that it may be poorly implemented. Globally, approximately half of all deaths in under five 
children are link to malnutrition, translating into the loss of about 3 million lives a year [5].The prevalence of stunting, wasting and underweight for children under 5 years are $19 \%, 5 \%$ and $11 \%$ respectively in Ghana and $33.1 \%, 6.3 \%$ and $20 \%$ respectively in Northern region [11]. Malnutrition puts children at greater risk of dying from common infections, increases the frequency and severity of such infections, and delays recovery [5].

It has been established in other settings that poor knowledge on growth monitoring among mothers is associated with poor implementation of growth monitoring $[9,12]$ which results in high malnutrition rate. However, growth monitoring knowledge among mothers and its relation to child nutritional status is unknown in the Tamale Metropolis. Hence this study sought to assess maternal growth monitoring knowledge and its effect on nutritional status of children $0-18$ months in the Tamale Metropolis.

\section{Main text \\ Methodology \\ Study design, study setting and sampling}

An analytical cross-sectional study design was employed and involved 340 mother-child pairs selected from 4 health facilities (Tamale Central Hospital, Reproductive and Child Health Centre, Nyohini Health Centre and Bulpiela Health Centre) in the Tamale Metropolis. The study was carried out from May 10 to June 15, 2018. Simple random sampling method was used in selecting the 4 study health facilities from all (10) the public health facilities in the Tamale Metropolis. Mothers with children aged 0-18 months attending the child welfare clinics of the selected health facilities were eligible for the study. Subjects who were very ill (unstable vital signs/mental status) were excluded from the study.

Sample size was determined using the formula [13]:

$$
\mathrm{N}=\frac{z^{2} p(1-p)}{M \cdot E^{2}}
$$

where $\mathrm{N}$ is the sample size; $\mathrm{z}$ is the abscissa of the normal curve that cut-off an area at the tail (1.96); $\mathrm{P}$ is the estimated proportion of an attribute (stunting) that is present in the study population, which is $33.1 \%$ [11] in Northern region; M.E is the desired level of precision $(5 \%=0.05)$.

$$
\mathrm{N}=\frac{(1.96)^{2} 0.331(1-0.331)}{(0.05)^{2}}=340
$$

Therefore, sample size for the study was 340 respondents.

\section{Data collection}

A pretested structured questionnaire was used to document information on participants' demographic characteristics (sex of child, age of mother and child, mothers' educational level, religion, occupation and marital status) and level of maternal knowledge on growth monitoring. Regarding growth monitoring knowledge, the questionnaire items were adapted from similar studies $(9,14)$. A composite score was on mothers' responses to the questions. A score of 1 (maximum score) was assigned to a correct response while a score of 0 (minimum score) was assigned to an incorrect response. Mothers who scored $0-4$ for the knowledge questions were considered to have poor knowledge while those who scored 5-8 for the knowledge questions were considered to have good knowledge. Anthropometric measurements (length and weight) of the children were taken and nutritional status (stunting, wasting and underweight) assessed in accordance with WHO standards [14]. Length of children was measured using an infantometre to the nearest $0.1 \mathrm{~cm}$. Weight of children was measured using a digital electronic weighing scale (Seca 874) to the nearest $0.1 \mathrm{~kg}$. Height-for-age Z-score (HAZ), weight-for-height Z-score (WHZ), and weight-for-age $Z$-score $(W A Z)<-2$ standard deviations $(-2 \mathrm{SD})$ from the median of the WHO Growth Standards were defined as stunting, wasting, and underweight respectively.

\section{Statistical analysis}

Data entry and analysis was done using Statistical Package for Social Sciences (SPSS) (IBM, version 21) and WHO Anthro software. Chi square/Fisher's exact test was used to determine the association between maternal growth monitoring knowledge level and child nutritional status (stunting, wasting and underweight). $\mathrm{p}<0.05$ was considered significant at two tailed tests. Percentages and cross tabulations were used to show respondents' responses.

\section{Results \\ Socio-demographic characteristics of the study sample}

The mean age of mothers was $29.26 \pm 5.64$ years with the minimum and maximum ages of 17 and 50 years respectively. Most of the mothers (44.7\%) had no formal education, with $96.8 \%$ being married. Moreover, majority of the mothers were self-employed (71.8\%), belonged to Dagomba ethnic group (80.9\%) and Islamic religion (93.8\%). The mean age of children was $5.7 \pm 4.3$ months, with majority of them in the age group 0-5 months (57.4\%). Also, majority of the children were males (51.5\%). 
Table 1 Socio-demographic characteristics

\begin{tabular}{|c|c|c|}
\hline Characteristic & Category & Frequency (\%) \\
\hline \multirow[t]{3}{*}{ Age of mother (years) } & $17-27$ & $146(42.9)$ \\
\hline & $28-37$ & $158(46.5)$ \\
\hline & $>38$ & $36(10.6)$ \\
\hline \multirow[t]{5}{*}{ Education } & None & $152(44.7)$ \\
\hline & Primary & $31(9.1)$ \\
\hline & Middle/JHS & $59(17.4)$ \\
\hline & SHS/vocational training & $51(15)$ \\
\hline & Tertiary & $47(13.8)$ \\
\hline \multirow[t]{3}{*}{ Occupation } & Employed & $38(11.2)$ \\
\hline & Self employed & $244(71.8)$ \\
\hline & Unemployed & $58(17)$ \\
\hline \multirow[t]{4}{*}{ Ethnicity } & Dagomba & $275(80.9)$ \\
\hline & Gonja & $19(5.6)$ \\
\hline & Mamprusi & $11(3.2)$ \\
\hline & Others & $35(10.3)$ \\
\hline \multirow[t]{2}{*}{ Religion } & Christianity & $21(6.2)$ \\
\hline & Islam & $319(93.8)$ \\
\hline \multirow[t]{3}{*}{ Age of child (months) } & $0-5$ & $195(57.4)$ \\
\hline & $6-11$ & $102(30)$ \\
\hline & $12-18$ & $43(12.6)$ \\
\hline \multirow[t]{2}{*}{ Sex of child } & Male & $175(51.5)$ \\
\hline & Female & $165(48.5)$ \\
\hline
\end{tabular}

Table 1 depicts the socio-demographic characteristics of respondents.

\section{Maternal growth monitoring knowledge level}

Table 2 shows maternal growth monitoring knowledge level. Majority of the mothers referred to weighing $(80.6 \%)$ as the meaning of growth monitoring. A large section $(85.6 \%)$ of the mothers said growth monitoring is important as it determines the child's nutritional status. Also, majority (92.9\%) said every mother ought to attend growth monitoring sessions once every month. Some of the mothers $(31.8 \%)$ said the growth chart represents the growth of the child. With regards to overall knowledge level of mothers, $12.4 \%$ had poor knowledge while $87.6 \%$ had good knowledge.

\section{Nutritional status of children}

The mean HAZ, WHZ and WAZ were $0.1 \pm 1.7$, $-1.08 \pm 1.75$ and $-0.78 \pm 1.4$ respectively (Additional file 1). The prevalence of stunting, wasting and underweight were $9.4 \%, 25.9 \%$ and $17.9 \%$ respectively (Additional file 2). It was also revealed in the present study that stunting and underweight were significantly associated with maternal education $(\mathrm{p}=0.008)$ and age of child $(\mathrm{p}=0.003)$ respectively (Additional file 3$)$.

\section{Relationship between maternal growth monitoring knowledge and child nutritional status}

It was revealed in the present study that the association between maternal growth monitoring knowledge and stunting $(\mathrm{p}=0.781)$, underweight $(\mathrm{p}=0.529)$ and wasting $(\mathrm{p}=0.743)$ is statistically insignificant as shown in Table 3.

\section{Discussion}

With regards to knowledge level of mothers on growth monitoring, the study revealed that majority $(80.6 \%)$ of respondents chose weighing as the meaning of growth monitoring. This finding is comparable to that of Debuo et al. [9] in Lawra District, Upper West Region of Ghana, where $70.3 \%$ of mothers chose weighing as the meaning of growth monitoring. This indicates that there has been a lot of education on growth monitoring among mothers in both districts. Apart from massive education, it could also mean that the health personnel used similar approaches in delivering information to mothers. The present study also revealed that $85.6 \%$ of mothers thought growth monitoring improves children's nutritional status and subsequently growth. This finding is similar to findings of other studies $[9,15]$. In addition, $92.9 \%$ of participants in the current study said that growth monitoring is provided every month. A similar study by Daniel et al. [15] in Ethiopia revealed that $32.1 \%$ of the respondents said growth monitoring services is provided every month. The difference in findings could be due to the fact that mothers in Ethiopia did not receive adequate education on interval of growth monitoring visits as compared to mothers in Ghana. It could also be due to differences in health policy implementation between Ghana and Ethiopia. Furthermore, $98.5 \%$ of the respondents know when growth monitoring services should begin. In a similar study [15], a higher percentage $(68.2 \%)$ of mothers knew when growth monitoring services ought to begin. If mothers know when growth monitoring is supposed to begin then there is a high probability that mothers will start growth monitoring early and could reap the full benefits of growth monitoring services. This study also uncovered that $32.1 \%$ of mothers felt growth monitoring was for children between the ages of 0-5 years. This finding is also in consonance with that of Daniel et al. [15].

Regarding the overall knowledge level of mothers on growth monitoring, $87.6 \%$ of the mothers had good knowledge in the present study. Similarly, a good knowledge level was also reported in studies conducted in Ghana $[9,16]$ and other parts of the world $[17,18]$. Contrarily, a study by Daniel et al. [15] revealed that $53 \%$ of 
Table 2 Maternal growth monitoring knowledge

\begin{tabular}{|c|c|c|}
\hline Characteristic & Category & Frequency (\%) \\
\hline \multirow[t]{3}{*}{ When you hear growth monitoring, what comes to mind? } & Weighing & $274(80.6)$ \\
\hline & Immunization & $62(18.2)$ \\
\hline & Treatment of malnourished children & $4(1.2)$ \\
\hline \multirow[t]{4}{*}{ Importance of growth monitoring } & Determines child's nutritional status & $291(85.6)$ \\
\hline & Educates about appropriate child feeding & $44(12.9)$ \\
\hline & Don't know & $4(1.2)$ \\
\hline & Not important & $1(0.3)$ \\
\hline \multirow[t]{4}{*}{ Number of times one is supposed to go for growth monitoring sessions } & Once a month & $316(92.9)$ \\
\hline & Twice every month & $15(4.4)$ \\
\hline & Once every 6 months & $4(1.2)$ \\
\hline & Don't know & $5(1.5)$ \\
\hline \multirow[t]{3}{*}{ When is one to start going forgrowth monitoring sessions? } & At birth & $282(82.9)$ \\
\hline & At 1 month of age & $53(15.6)$ \\
\hline & At 1 year of age & $5(1.5)$ \\
\hline \multirow[t]{3}{*}{ Age range for growth monitoring } & Children $<2$ years of age & $208(61.2)$ \\
\hline & Children $0-5$ years of age & $110(32.3)$ \\
\hline & Don't know & $22(6.5)$ \\
\hline \multirow[t]{4}{*}{ One responsible for growthmonitoring provision } & Nurses & $321(94.4)$ \\
\hline & Midwives & $10(2.9)$ \\
\hline & Doctors & $8(2.4)$ \\
\hline & Teachers & $1(0.3)$ \\
\hline \multirow[t]{3}{*}{ Where growth monitoring services are provided? } & Hospitals & $79(23.2)$ \\
\hline & Health centers & $248(72.9)$ \\
\hline & Don't know & $13(3.8)$ \\
\hline \multirow[t]{4}{*}{ What does a growth chart represent? } & It shows the age of child & $63(18.5)$ \\
\hline & It shows how the child is growing & $107(31.5)$ \\
\hline & It has no meaning & $28(8.2)$ \\
\hline & Don't know & $142(41.8)$ \\
\hline \multirow[t]{2}{*}{ Knowledge level } & Poor knowledge & $42(12.4)$ \\
\hline & Good knowledge & $298(87.6)$ \\
\hline
\end{tabular}

mothers had poor knowledge on growth monitoring, which could be due to inadequate education on growth monitoring in this setting.

The prevalence of stunting in the sampled population was $9.4 \%$. This result is much lower than the Northern regional prevalence of $33.1 \%$ reported in the most recent Ghana Demographic Health Survey (GDHS) in 2014 [11]. It is also lower than the national stunting prevalence of $18.7 \%$ reported by WHO in 2014 [19]. The present study was conducted among children aged 0-18 months while that of GDHS and WHO were among children under 5 years, this methodological difference could partly account for the lower prevalence recorded in the present study. It is also worth noting that the prevalence rates reported by GDHS and WHO were average figures for Northern region and Ghana respectively, suggesting that other places in the Northern region or Ghana could have lower prevalence rates, hence the finding of the present study. Moreover, the decreasing trend in stunting prevalence in the Northern region since 2011 could also account for the low prevalence reported in the present study. The prevalence of stunting decreased from $37.4 \%$ in 2011 [20] to $33.1 \%$ in 2014 [11]. Although the prevalence of stunting is on the decrease, the finding of the present study shows that it is still a public health concern in Northern region of Ghana. The prevalence rates of underweight and wasting were $25.9 \%$ and $17.9 \%$ respectively in the present study. Regarding underweight, the prevalence rate in the current study was higher than the prevalence rates in Northern region of Ghana (20\%) [11] and Ghana as a whole (11.2\%) [19]. Similarly, the prevalence of wasting in the present study was higher than the prevalence rates in Northern region (6.3\%) [11] and Ghana (5\%) [19]. Again, the difference in methodologies employed may partly explain the difference in findings between the present and previous studies. Also, the 
Table 3 Relationship between maternal growth monitoring knowledge and stunting, wasting and underweight

\begin{tabular}{|c|c|c|c|c|}
\hline \multirow[t]{2}{*}{ Characteristic } & \multicolumn{4}{|l|}{ Stunting } \\
\hline & Stunted N=32 (\%) & Not stunted N=308 (\%) & Total $\mathrm{N}=340(\%)$ & p-value \\
\hline \multicolumn{5}{|l|}{ Knowledge level } \\
\hline Poor knowledge & $3(7.1)$ & $39(92.9)$ & $42(100)$ & \multirow[t]{2}{*}{0.781} \\
\hline Good knowledge & $29(9.7)$ & $269(90.3)$ & $298(100)$ & \\
\hline \multirow[t]{2}{*}{ Characteristic } & \multicolumn{4}{|l|}{ Underweight } \\
\hline & Underweight $\mathrm{N}=61$ (\%) & Not underweight $\mathrm{N}=279$ (\%) & Total N=340 (\%) & p-value \\
\hline \multicolumn{5}{|l|}{ Knowledge level } \\
\hline Poor knowledge & $9(21.4)$ & $33(78.6)$ & $42(100)$ & \multirow[t]{2}{*}{0.529} \\
\hline Good knowledge & $52(17.4)$ & $246(82.6)$ & $298(100)$ & \\
\hline \multirow[t]{2}{*}{ Characteristic } & \multicolumn{4}{|l|}{ Wasting } \\
\hline & Wasted N = $88(\%)$ & Not wasted $252(\%)$ & Total N=340 (\%) & $p$-value \\
\hline \multicolumn{5}{|l|}{ Knowledge level } \\
\hline Poor knowledge & $10(23.8)$ & $32(76.2)$ & $42(100)$ & \multirow[t]{2}{*}{0.743} \\
\hline Good knowledge & $78(26.2)$ & $220(73.8)$ & $298(100)$ & \\
\hline
\end{tabular}

high prevalence rates of underweight and wasting in the present study could be an indication that enough emphasis has not been laid on interventions geared towards tackling underweight and wasting in the Metropolis. Although underweight among children under five is not considered public health concern in Ghana [20] and Northern region [11], this study has shown that underweight should be considered a public health concern for children between 0-18 months in the Tamale Metropolis.

Moreover, no association was established between maternal growth monitoring knowledge level and stunting, underweight and wasting. On the other hand, a study revealed a significant association between underweight $(\mathrm{p}=0.02)$ and maternal growth monitoring knowledge [21]. The variation in findings could be attributed to differences in attitudes and practices of mothers in relation to growth monitoring in both settings. The finding of the present study shows that good maternal knowledge of growth monitoring does not automatically translates to improved child nutritional status, unless it is coupled with good attitude and practices of growth monitoring.

\section{Conclusion}

Growth monitoring knowledge level of the mothers is high, but has no effect on stunting, wasting and underweight among children 0-18 months in the Tamale Metropolis.

\section{Limitations}

The cross-sectional nature of the study does not provide a good basis for determining causality as both exposure and outcome were assessed simultaneously. Moreover, nutritional status of the mothers was not assessed. This notwithstanding, we trust the study shed some light on the effect of maternal growth monitoring knowledge on child nutritional status in the Tamale Metropolis.

\section{Supplementary information}

Supplementary information accompanies this paper at https://doi. org/10.1186/s13104-020-4910-z.

Additional file 1. Nutritional status indicators.

Additional file 2. Nutritional status of children.

Additional file 3. Nutritional status by socio-demographic characteristics of respondents.

\section{Abbreviations}

GDHS: Ghana Demographic Health Survey; HAZ: Height-for Age-Z-score; M. E: marginal error; WAZ: Weight-for-Age-Z-score; WHO: World Health Organization; WHZ: Weight-for-Height-Z-score.

\section{Acknowledgements}

The authors would like to thank the mothers who willingly consented to participate in this study. We also wish to thank all the staff of the health facilities for their support during the study.

\section{Authors' contributions}

Authors MB, MMA, MM and AA designed the study. Author MB, MMA, MM performed field data collection. Authors MB, MMA and AA analyzed the study results. MB and AA wrote the first draft of the manuscript. Authors A-RA and $\mathrm{AW}$ contributed to the writing of the manuscript. All authors read and approved the final manuscript.

Funding

We did not receive funding for this study. 


\section{Availability of data and materials}

The datasets used and/or analyzed during the current study are available from the corresponding author on reasonable request.

\section{Ethics approval and consent to participate}

Approval to conduct the study was given by the Joint Ethical Review Committee of the School of Medicine and Health Sciences and School of Allied Health Sciences, University for Development Studies (Protocol Number 05-2018). Permission was obtained from the Tamale Metropolitan Health Directorate and the hospitals of study. Written informed consent was also obtained from participants after providing them with sufficient information about the study. Regarding participants who were less than 18 years of age, written informed consent was obtained from their parents. Participants were also assured of the confidentiality of the information provided.

\section{Consent for publication}

Not applicable.

\section{Competing interests}

The authors declare that they have no competing interests.

Received: 17 October 2019 Accepted: 16 January 2020

Published online: 29 January 2020

\section{References}

1. Griffiths M, Rosso JD. Growth monitoring and the promotion of healthy young child growth: evidence of effectiveness and potential to prevent malnutrition. Washington, DC: Manoff Group; 2007. p. 36.

2. Österberg, M., Nursing staff' s experiences of working with children's growth monitoring and promotion in Zambia. 2016.

3. Panpanich, R, Garner P. Growth monitoring in children. Cochrane Database Syst Rev. 1999(4)

4. Garner P, Panpanich R, Logan S. Is routine growth monitoring effective? A systematic review of trials. Arch Dis Child. 2000;82(3):197-201.

5. UNICEF. Revisiting growth monitoring and its evolution to promoting growth as a strategic program approach: building consensus for future program guidance. Report of the technical consultation on growth monitoring and promotion. Book revisiting growth monitoring and its evolution to promoting growth as a strategic program approach: building consensus for future program guidance. Report of the technical consultation on growth monitoring and promotion. 2007.

6. Schwinger C, Fadnes LT, Van den Broeck J. Using growth velocity to predict child mortality, 2. Am J Clin Nutr. 2016;103(3):801-7.
7. Sinaga $\mathrm{HT}$, et al. Using scores in interpreting growth status effectively improved infant feeding practices and calorie intake of child aged 0-12 months. Int J Med Sci Public Health. 2016:5:1014-20.

8. De Onis M, Wijnhoven TM, Onyango AW. Worldwide practices in child growth monitoring. J Pediatr. 2004;144(4):461-5.

9. Debuo TD, et al. Caregivers knowledge, attitude and practices on child growth monitoring and promotion activities in Lawra District, Upper West Region of Ghana. Sci J Public Health. 2017;5:20-30.

10. Service G.S. Population and housing census: district analytical report. Agotime Ziope District: Ghana statistical service; 2014.

11. Service, G.S. Ghana demographic and health survey, 2014. Maryland: GSS, GHS, and ICF International; 2015.

12. Roberfroid D, et al. Perceptions of growth monitoring and promotion among an international panel of district medical officers. J Health Popu Nutr. 2005;23:207-14

13. Cochran WG. Sampling techniques. New York: Wiley; 2007.

14. Organization, W.H. WHO child growth standards: length/height for age, weight-for-age, weight-for-length, weight-for-height and body mass index-for-age, methods and development. Geneva: World Health Organization; 2006.

15. Daniel B, et al. Knowledge and attitude on growth monitoring and its associated factors among mothers/guardians of children less than 2 Years in Areka Town, southern Ethiopia, 2017. J Nutr Disord Ther. 2017;7(216):2161-0509.1000216.

16. Gyampoh S, Otoo GE, Aryeetey RNO. Child feeding knowledge and practices among women participating in growth monitoring and promotion in Accra, Ghana. BMC Pregnancy Childbirth. 2014;14(1):180.

17. Wamani $\mathrm{H}$, et al. Infant and young child feeding in western Uganda: knowledge, practices and socio-economic correlates. J Trop Pediatr. 2005;51(6):356-61.

18. Otoo GE, Lartey AA, Pérez-Escamilla R. Perceived incentives and barriers to exclusive breastfeeding among periurban Ghanaian women. J Hum Lactation. 2009:25(1):34-41.

19. World Health Organisation. Global database on child growth and malnutrition. 2019. https://www.who.int/nutgrowthdb/database/en/. Accessed 10 Oct 2019.

20. Ghana Statistical Service G. Ghana multiple indicator cluster survey with an enhanced malaria module and biomarker. Final Report. 2011.

21. Ashworth A, Shrimpton R, Jamil K. Growth monitoring and promotion: review of evidence of impact. Matern Child Nutr. 2008:4:86-117.

\section{Publisher's Note}

Springer Nature remains neutral with regard to jurisdictional claims in published maps and institutional affiliations.
Ready to submit your research? Choose BMC and benefit from:

- fast, convenient online submission

- thorough peer review by experienced researchers in your field

- rapid publication on acceptance

- support for research data, including large and complex data types

- gold Open Access which fosters wider collaboration and increased citations

- maximum visibility for your research: over 100M website views per year

At BMC, research is always in progress.

Learn more biomedcentral.com/submissions 